\title{
Integrasi RUP dan DSDM untuk Rancang Bangun Sistem Informasi Olahraga yang Komprehensif Studi Kasus: Pengurus Besar Taekwondo Idonesia
}

\author{
Muhammad Rizky Pribadi \\ Program Studi Sistem Informasi \\ STMIK MDP \\ $\underline{\text { rizky@mdp.ac.id }}$
}

\begin{abstract}
Abstrak - Dalam paper ini, penulis membahas beberapa isu metodologi terkait dengan pembangunan sistem informasi olahraga, dan menggambarkan mafaat yang diberikan kedapa organisasi olahraga terhadap penerapan sistem informasi dalam operasional organisasi. Dalam paper ini PBTI dipilih sebagai study kasus. Penulis membahas dalam paper ini manfaat menggunakan penelitian sebagai mekanisme untuk menjelajahi masalah terkait guna membentuk sebuah sistem informasi olahraga yang ideal.
\end{abstract}

Kata Kunci-Sistem Informasi Olahraga, PBTI, Metodologi

\section{PENDAhUluan}

Indonesia merupakan negara kepulauan terbesar di dunia dengan jumlah penduduk terbesar nomor empat didunia, hal ini membuat Indonesia merupakan sebuah potensi kekuatan besar dalam dunia olahraga, tapi dengan semua kelebihan tersebut belum bisa menghasilkan prestasi yang luar biasa di tingkat internasional. Hingga saat ini pun Indonesia masih belum bisa merajai olahraga di tingkat ASEAN yang wilayah teritorial nya jauh lebih kecil dibanding Indonesia.

Hal yang menjadi penghambat tumbuhnya prestasi olahraga di Indonesia adalah belum menerapkan sistem informasi pada proses organisasinya. Organisasi olahraga di Indonesia masih bersifat manual. Dengan luas area yang sangat luas tentu saja jika dikelola degan manual akan sangat tidak efektif.

Saat ini organisasi yang mengurus semua cabang olahraga di Indonesia adalah KONI. KONI merupakan induk dari seluruh organisasi olahraga di Indonesia. KONI berada dibawah naungan DISPORA. Salah satu organisasi olahraga yang berada dibawah naungan KONI adalah PBTI (Pengurus Besar Taekwondo Indonesia). PBTI merupakan organisasi olahraga yang mengurus cabang olahrga Taekwondo.

Pada saat ini PBTI dalam semua urusan belum memiliki sebuah sistem informasi yang terintegrasi, sehingga semua pengelolaan data masih tradisional. Apabila dibangun sebuah sistem informasi yang terintegrasi maka tentu akan sangat berguna bagi organisasi ini. Sistem informasi yang dibangun akan memudahkan organisasi dalam urusan pengolahan data.

Contoh kasusnya adalah pada saat ujian kenaikan tingkat PBTI masuh menggunakan cara tradisional dalam pendaftaran.
Tiap-tiap peserta ujian mengisi formulir ujiaan, kemudian dikumpulkan ke ranting masing-masing. Setelah itu dari ranting meyerahkan ke Pengcab (Pengurus Cabang), dari Pengcab merekap semua data ujian kedalam sebuah file excel yang akan diserahkan kepada Pengkab/Pengkot(Pengurus Kabupaten/Kota). Setelah itu Pengkab/kot melakukan ujian. Data dari peserta ujian yang lulus akan diserahkan kepada Pengprov (Pengurus Provinsi). Pengurus Provinsi biasanya memerlukan waktu sekitar tiga bulan untuk merekap data-data peserta ujian yang lulus. Hal ini tentu sangat membuang-buang waktu. Jika sudah diterapkan sebuah sistem pendaftaran online, maka tidak akan adalagi kegiatan pengumpulan berkas formulir ujian yang luar biasa banyak. Sistem dengan mudah merekap data-data peserta ujian secara otomatis. Tentu pekerjaan dari organisasi akan semakin cepat. Organisasi bisa mengerjakan hal lain yang dapat berguna untuk menaikkan prestasi olahraga.

Contoh kasus lainnya adalah tidak adanya sebuah sistem yang megelola data pembinaan atlet. Semua data atlet hanya disimpan dalam bentuk file world atau excel. Sehingga data tersebut tidak dapat dimanfaatkan sebagai penunjang manajemen dalam mengambil tindakan terhadap apa yang diperlukan oleh atlet yang bersangkutan. Jika dibuat sebuah sistem pengolahan data atlet, yang menyimpan semua riwayat medis dan perkembangan dari kemampuan atlet maka itu akan sangat berguna bagi manajemen dalam mengambil keputusan terhadap tidakan yang diperlukan terhadap atlet. Contoh manfaatnya adalah seorang atet peremmpuan riwayat medisnya dicatat termasuk tanggal menstruasinya, jika ada sebuah kejuaraan yang akan diikuti oleh atlet perempuan itu bertepatan dengan tanggal mens si atlet perempuan, maka sistem secara otomatis memberikan peringatan kepada manajemen untuk melakukan tindakan medis dari jauh-jauh hari agar si atlet perempuan pada saat tanggal kejuaraan tidak mens. Dengan begitu atlet perempuan dapat tetap bertanding dan peluang juara akan semakin besar.

Dengan beberapa contoh yang saya ceritakan diatas tentu organisasi olahraga di Indonesia sangat membutuhkan sebuah sistem informasi agar dapat menunjang kegiatan organisasi olahraga menjadi lebih mudah dan bisa menghasilkan prestasi yang lebih baik. Maka dari itu saya mengusulkan untuk pembuatan sistem informasi olahraga dalam proyek akhir ini. 


\section{LANDASAN TEORI}

\section{A. Sistem Informasi Olahraga}

Sistem informasi olahraga adalah sebuah sistem informasi yang dibuat khusus untuk membantu manajemen dan pelaku olahraga dalam hal pengelolaan rutinitas olahraga dalam suatu organisasi olahraga. Menurut Jensen Lin, dkk dalam paper yang berjudul "A Sports Information Management System Based On Pervasive Computing Technology", menyatakan bahwa, saat ini aplikasi teknologi komputasi yang semakin populer di era saat ini, tetapi tidak populer dalam dunia olahraga.

Kebanyakan manajemen olahraga masih mengumpulkan dan menganilisi data dengan tangan, diharapkan dengan teknologi komputer ini dapat digunakan untuk meningkatkan efisiensi untuk pengumpulan informasi dan analisis. Menurut Habib Honari, Ph. D dalam papernya yang berjudul "Information Technology in Professional Sports" mengatakan, dampak dari teknologi informasi pada olahraga profesional membuat struktur organisasi baru yang dikenal dengan $\mathrm{T}$ Shape.

Koordinasi antara staf melalui komunikasi elektronik akan dilakukan dan software yang dibangun untuk mengkoordinasikan kelompok. Menurut Jinhai Sun dalam Papernya berjudul The Establishment of Sports System Engineering as A Discipline mengatakan bahwa "Melalui analisis kebutuhan dan kelayakan pembentukan sistem olahraga mendefinisikan definisi Teknik Sistem Olahraga, menguraikan dan membuktikan sifatnya, fitur orientasi serta membangun sistem teori dan sistem metode.

\section{B. DSDM (Dynamic System Development Methodology)}

DSDM (Dynamic System Development Methodology) adalah non proprietary framework dikelola oleh DSDM symposium. DSDM symposium adalah sebuah organisasi nonprofit. DSDM adalah framework vendor independen.

DSDM adalah pendekatan sistematis menangani sebuah proyek secara efektif dan efisien. DSDM memfasilitasi kerangka yang menarik untuk mengembangkan fungsi dengan cara yang lebih baik dan amicable manner, memberikan fungsi secara efisien dan efektif, dan memuaskan kebutuhan nyata dari proyek.

Pengembangan sistem dinamis metode kerangka dikembangkan dalam lima tahap, yang pertama dua fase yang berurutan dan tiga terakhir adalah tambahan dan iteratif. Interval waktu juga disebut time box direncanakandengan baik sebelum dilaksanakan. Umumnya time box berasal dari beberapa hari untuk beberapaa minggu. Berikut life cycle dari DSDM diilustrasikan pada Gambar 1 .

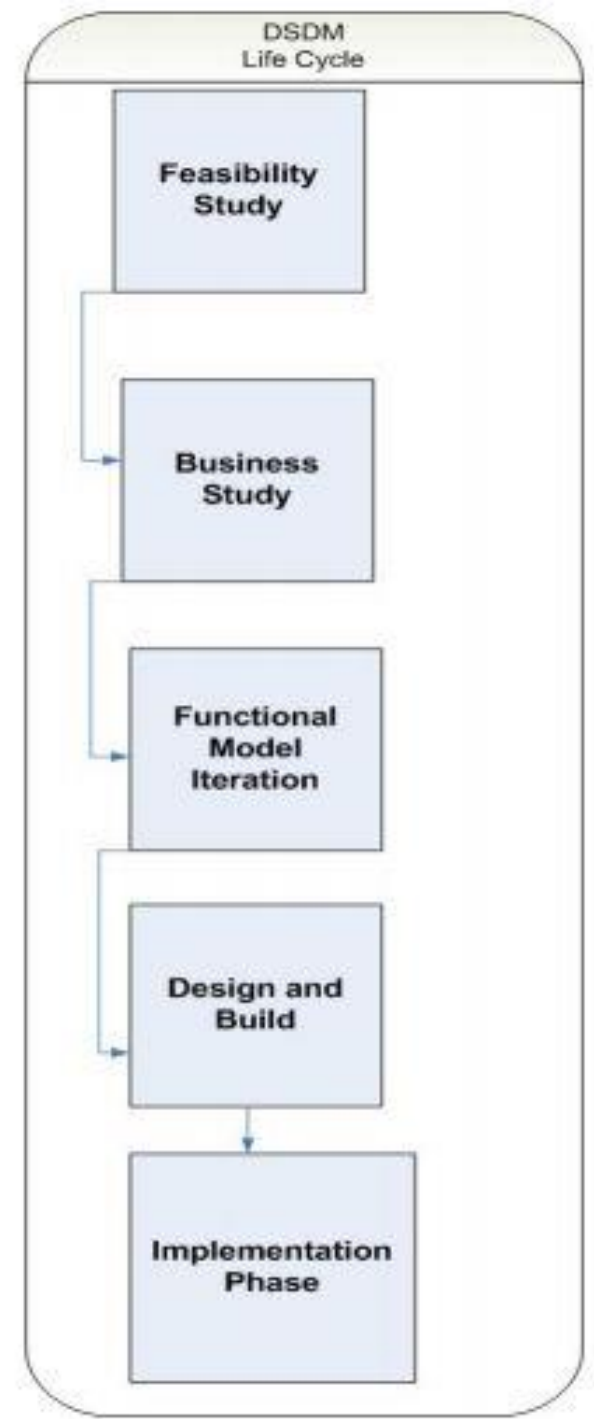

Gambar 1. Life Cycle of DSDM

\section{RUP (Rational Unified Process)}

Rational Unified Process (RUP) merupakan suatu metode rekayasa perangkat lunak yang dikembangkan dengan mengumpulkan berbagai best practises yang terdapat dalam industri pengembangan perangkat lunak. Ciri utama metode ini adalah menggunakan use-case driven dan pendekatan iteratif untuk siklus pengembangan perankat lunak. RUP menggunakan konsep object oriented, dengan aktifitas yang berfokus pada pengembangan model dengan menggunakan Unified Model Language (UML). 


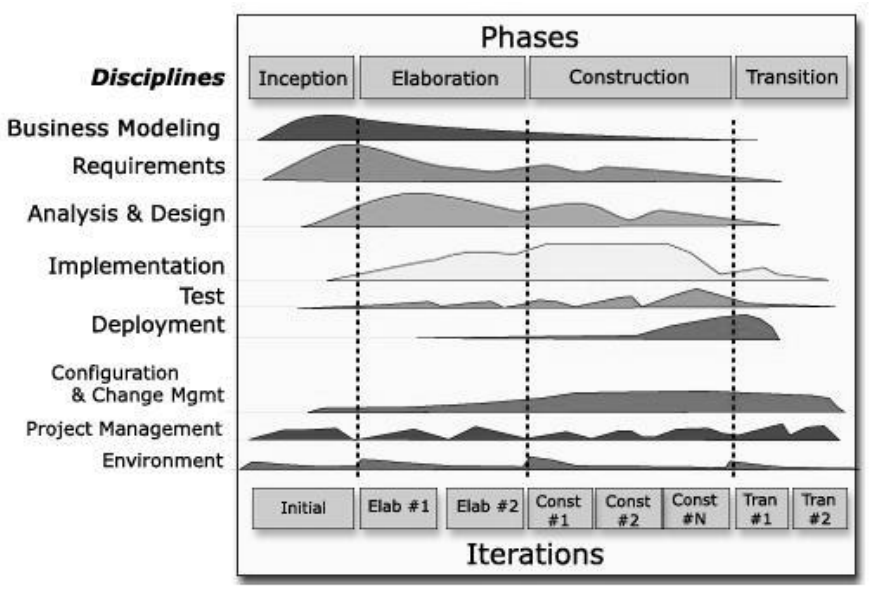

Gambar 2. Arsitektur RUP

\section{UML (Unified Modelling Language)}

Unified Modelling Language(UML) adalah sebuah bahasa yang telah menjadi standar dalam industri untuk visualisasi, merancang dan mendokumentasikan sistem piranti lunak. Bahasa pemodelan UML lebih cocok untuk pembuatan perangkat lunak dalam bahasa pemrograman berorientasi objek. Beberapa jenis diagram UML adalah : Use case Diagram, Class Diagram,Collaboration Diagram, Sequence Diagram, dan sebagainya.

\section{ISD APPROACH DAN METODOLOGI}

DSDM dan RUP adalah dua kerangka kerja paling efektif yang digunakan oleh pengembang perangkat lunak dan aplikasi pada saat ini. Seperti kerangka yang lainnya juga, masing-masing memiliki kelebihan dan keterbatasan tertentu. Untuk memaksimalkan kelebihan dan keterbatasan itu, pada proyek ini menggunakan sebuah penggabungan yang ideal dari dua kerangka.

DSDM menggunakan pendekatan proyek sebagai serangkaian langkah-langkah atau tahapan terpisah. Hal ini memungkinkan tim untuk mengembangkan dan memberikan solusi secara bertahap. Namun, DSDM tidak memberikan disiplin sebagai kerangka untuk menjamin kualitas. Karena terlalu sibuk mengurus prototype mengakibatkan dokumentasi proyek tidak lengkap.

RUP menyediakan pendekatan disiplin untuk pengembangan perangkat lunak berkualitas tinggi, tetapi dirancang untuk menghasilkan solusi tunggal yang diuji pada akhir siklus pengembangan. Dengan bekerja pada semua bagian solusi secara bersamaan, penunndaan satu bagian dapat mempengaruhi daerah lain atau menunda proyek secara keseluruhan. RUP karena terpaku pada UML maka hanya bisa pada proyek yang berbasi objek.

Pada proyek ini, penulis menemukan bahwa cara yang paling efektif untuk mengembangkan solusi kualitas tinggi dengan waktu yang cepat adalah dengan menggabungkan aspek disiplin RUP dengan pendekatan yang lebih bertahap dari DSDM. Dengan cara ini, kita dapat menghindari masalah yang berkaitan dengan perubahan dalam lingkup dan jadwal disesuaikan untuk memenuhi kebutuhan proyek tepat waktu, sesuai anggaran dan dokumentasi lengkap. Berikut gambar dari penggabungan DSDM dan RUP :

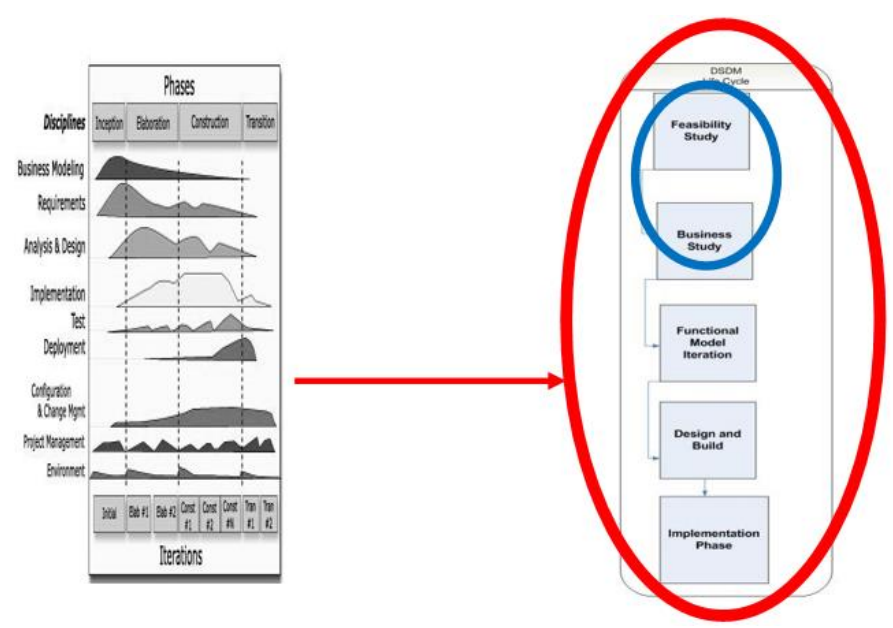

Gambar 3. RUP kombinasi DSDM

Dari gambar 3 penulis menggabungkan kedua metodologi menjadi kedalam satu metodologi. Dimana metodologi tersebut menjadi empat tahap. Pada metodologi DSDM tahapan feasibility study dan business study digabung dengan fase inception di RUP, Functional model iteration pada DSDM digabung dengan fase Elaboration di RUP, design and build pada DSDM digabung dengan fase construction di RUP, dan Implementation phase pada DSDM digabung dengan fase transition di RUP. Untuk lebih jelasnya berikut dijelaskan setiap keluaran dari setiap tahap demi tahap :

\section{A. DSDM Feasibility and Business Studies Phase Combine RUP Inception}

Ini merupakan fase pertama major project milestone dari ISDM yang digunakan. Pada point ini kriteria evaluasi nya adalah :

a) Menentukan definisi ruang lingkup dan perkiraan biaya/jadwal

b) Pemahaman kasus utama pada organisasi

c) Aktual biaya yang dikeluarkan dibandingkan pengeluaran yang direncanakan.

Pada fase ini akan menghasilkan Rich Picture, Glosary, Feasibility Report dan Feasibility Prototypes.

\section{1) Glosary}

Gloasary digunakan untuk kepentingan semua anggota proyek dalam pengembangan sistem agar memahami istilah-istalah dalam sebuah organisasi. Berikut merupakan glosary dalam proyek ini :
a) PBTI
: Pengurus Besar Taekwondo
Indonesia
b) Pengprov
c) Penkab
d) Pengkot
: Pengurus Provinsi
e) Club
: Pengurus Kota
: Perkumpulan Taekwondo 
f) Taekwondoin : Orang yang latihan Taekwondo

g) Geup 10-1: Sabuk Putih - Merah Strip 2

h) DAN : Sabuk Hitam

i) Dojang : Tempat latihan Taekwondo

j) Sabeum : Instruktur Taekwondo

\section{2) Rich Picture}

Rich Picture adalah penggambaran sistem atau situasi dengan menggunakan gambar-gambar. Gambaran keseluruhan dari orang, objek, proses, struktur, dan masalah pada keseluruhan proses bisnis yang ada di organisasi.

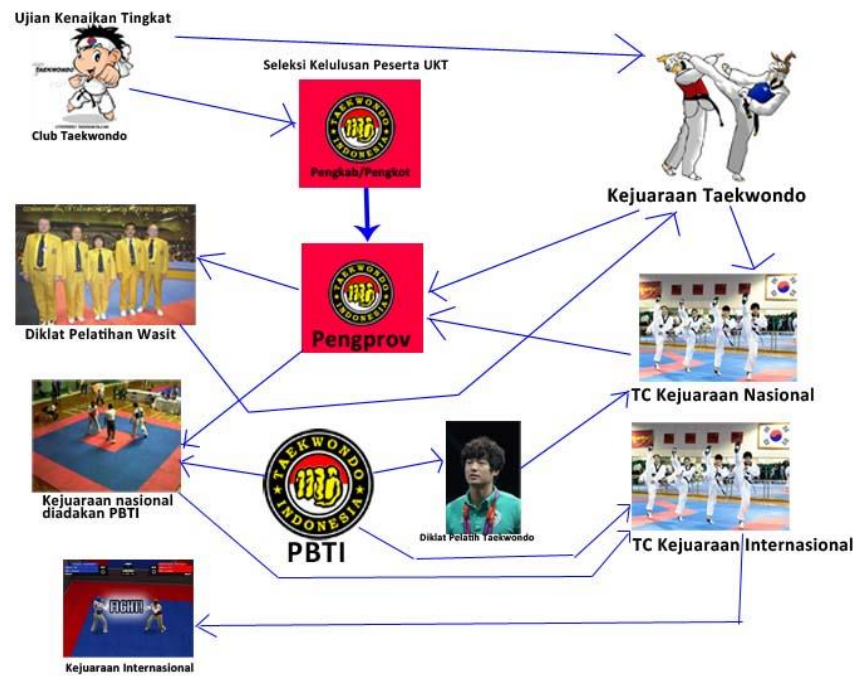

Gambar 4. Rich Picture PBTI

\section{3) Feasibility Report}

Setelah melihat Rich Picture dan melakukan beberapa wawancara maka didapatlah laporan feasibility report yang mencakup analisis kebutuhan, kelayakan teknis, dan kelayakan finansial.

a) Dari analisis kebutuhan, didapatkan hasil analisis bahwa PBTI sangat memerlukan sebuah sistem informasi yang dapat meningkatkan kinerja organisasi agar bisa mencapai visi dan misi organisasi.

b) Dari kelayakan teknis, didapatkan hasil bagian yang tepat untuk diprioritaskan dahulu dalam penerapan sistem informasi adalah Ujian Kenaikan Tingkat, Pengelolaan Kompetisi, dan Pengembangan Atlet. Karena, pada tiga bagian itu merupakan permasalahan yang paling banyak muncul selama ini, seperti terlambatnya sertifikat sabuk keluar, kejuaraan yang tidak berkesinambungan prestasi yang menurun.

c) Dari kelayakan finansial terhadap proyek ini maka didapatlah estimasi terhadap 2 aspek diatas, yaitu :

Start-up Cost :

Operating Cost

\section{4) Feasibility Prototypes}

Feasibility Prototypes digunakan untuk membuat sebuah gambaran aplikasi sederhana terhadap ketiga aplikasi yang akan dibuat, agar pihak PBTI memiliki sedikit gambaran tentang apa yang akan dibuat. Feasibility prototypes memungkinkan dapat memunculkan sebuah solusi baru terhadap proyek yang dilakukan ini.

\section{B. DSDM Functional Model Iteration Phase Combine RUP Elaboration}

Setelah tahapan study maka selanjutnya memasuki tahapan memeriksa tujuan sistem secara rinci dan ruang lingkup, pilihan arsitektur, dan resolusi resiko utama. Untuk melakukan semua hal ini maka diperlukan tools untuk memodelkannya, yaitu Business Area Definition, Use Case Model, Class Diagram, Activity Diagram, Sequence Diagram dan Interfaces.

1) Business Area Definition

a) Ujian Kenaikan Tingkat (UKT)

Process : Taekwondoin daftar online -> Admin Pengkab/Pengkot Sorting data pendaftara berdasarkan Geup -> Dilakukan Ujian -> Penguji memberi nama peserta yang lulus ke admin Pengprov -> Admin pengprov memasukkan data di web $\rightarrow$ Pengumuman kelulusan di web -> Data lulus dikirim ke Pengprov -> Pengprov Cetak Sertifikat $\rightarrow$ Pengkab/Pengkot memberikan sertifikat ke setiap club untuk dibagikan kepada peserta yang lulus.

Actor : Taekwondoin Peserta Ujian, Penguji, Pengkab/Pengkot, Pengprov, dan Club

\section{b) Pengelolaan Kejuaraan}

Process : Atlet yang bisa mengikuti kejuaraan minimal sabuk Biru, maka sistem pengelolaan harus terintegrasi dengan sistem informasi UKT agar mengetahui jumlah sabuk biru keatas ada berapa banyak. Sehingga jika sudah banyak harus diadakan kejuaraan. Ketersediaan wasit juga harus terdata didalam database pengelolaan kejuaraan, agar dapat mengetahui perlu atau tidaknya dilakukan diklat wasit untuk ketersediaan wasit untuk kejuaraan didaerah.

Actor : Atlet, Wasit, Club, Pengkab/Pengkot dan Pengprov

\section{c) Pengembangan Atlet}

Process : Dari sistem pengelolaan kejuaraan didapatkan para juara-juara. Nama-nama tersebut akan dimasukkan kedalam Pelatihan Daerah. Nama tersebut akan diolah oleh sistem pengembangan atlet selama karantina. Semua data medis dan progress latihannya disimpan dan diolah didalam database untuk keperluan dirinya dan program latihan yang perlu diberikan. 


\section{2) Use Case Model}

Use case model merupakan pemodelan struktural yang mencerminkan fungsionalitas sistem. Use case model menunjukkan apa yang bisa dilakukan oleh sistem. Berikut salah satu use case model dalam proyek ini :

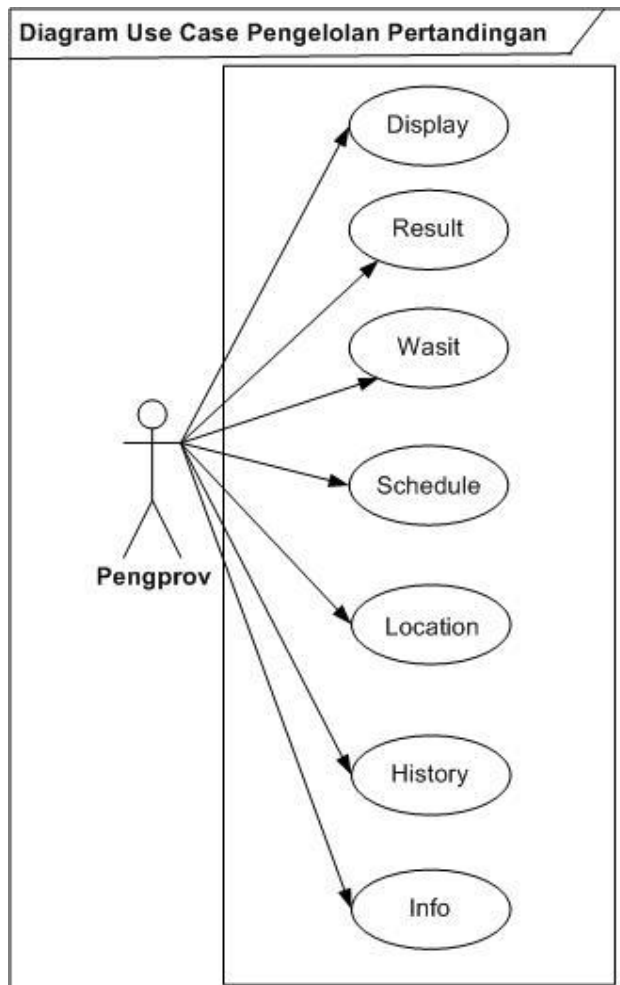

Gambar 5. Use Case Pengelolaan Pertandingan

\section{3) Class Diagram}

Class diagram digunakan untuk menampilkan kelaskelas dan paket-paket didalam sistem. Class diagram memberikan gambaran sistem secara statis dan relasi antara mereka. Class diagram dibuat untuk membuat pengembang mendapatkan struktur sistem sebelum kode ditulis, dan membantu untuk memastikan bahwa sistem adalah desain terbaik. Berikut salah satu class diagram dari aplikasi pengelolaan Kejuaraan Taekwondo.

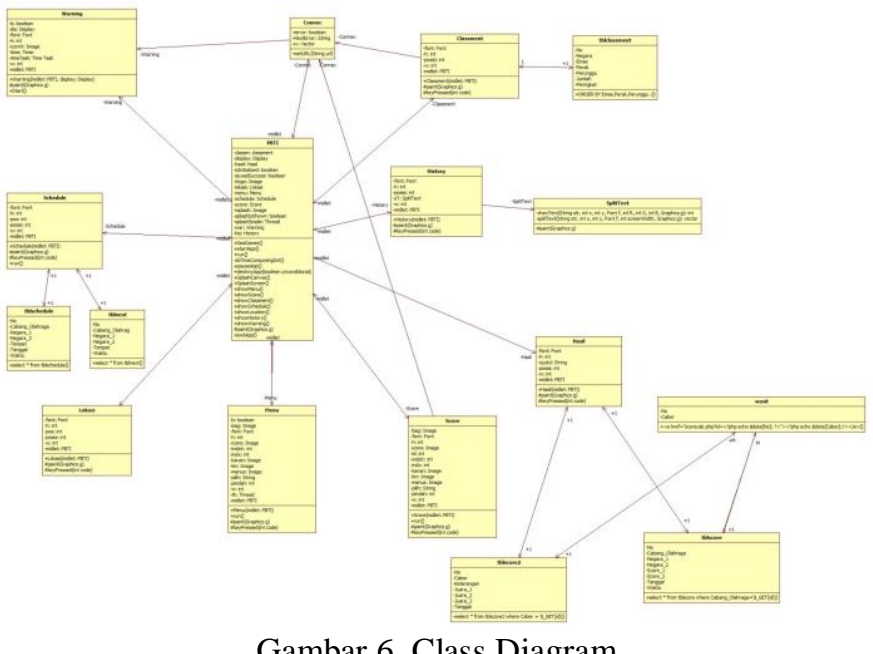

4) Activity Diagram

Activity Diagram adalah representasi grafis dari alur kerja tahapan aktivitas. Diagram ini mendukung pilihan tindakan, iterasi dan concureency. Pada pemodelan UML activity diagram dapat digunakan untuk menjelaskan bisnis dan alur kerja profesional secara step by step dari komponen suatu sistem. Berikut merupakan salah satu Activity Diagram dari proyek ini :

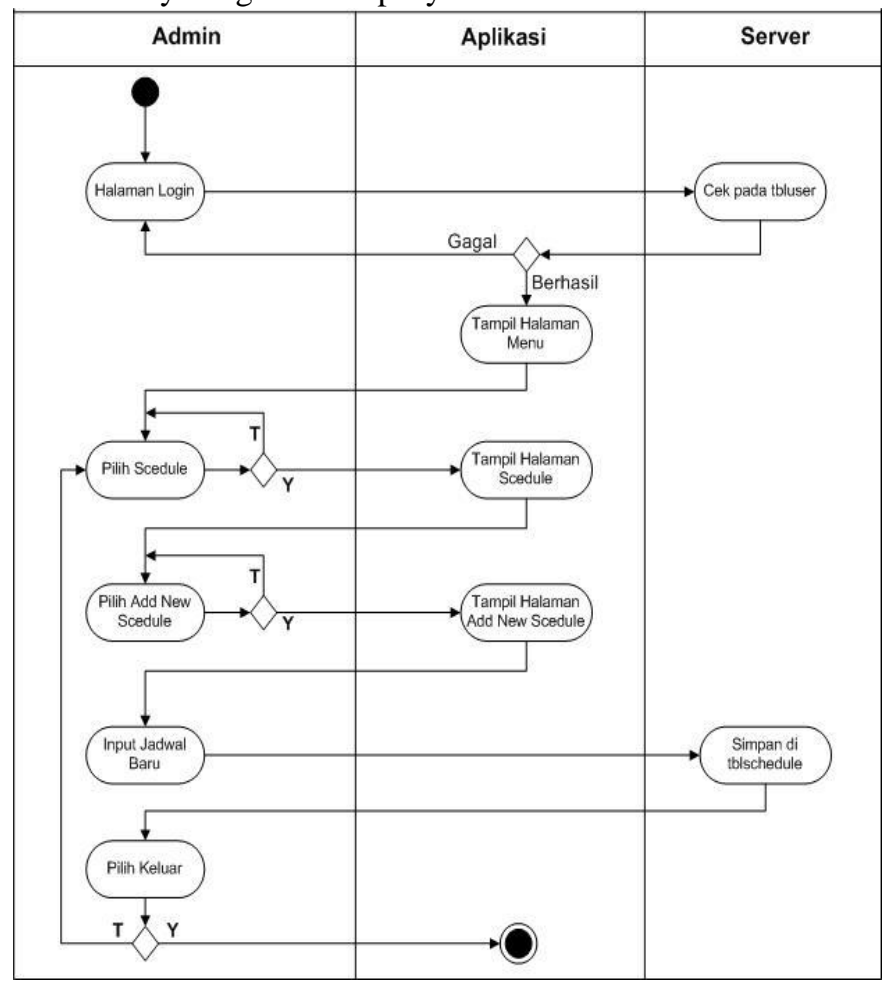

Gambar 7. Activity Diagram Add New Schedule Kejuaraan

\section{5) Sequence Diagram}

Sequence Diagram adalah suatu diagram yang menggambarkan interaksi antar obyek dan mengindikasikan komunikasi diantara obyek-obyek tersebut. Obyek-obyek diurutkan dari kiri ke kanan, aktor 
yang menginisiasi interaksi biasanya ditaruhh di paling kiri dari diagram.

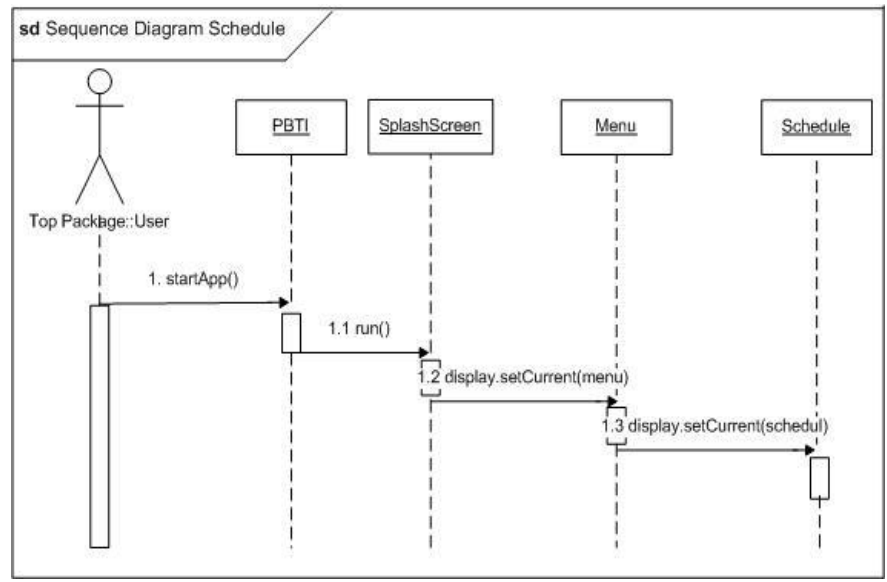

Gambar 8. Sequence Diagram Schedule Kejuaraan

\section{DSDM Design and Build Iteration Phase Combine RUP Construction}

Pada tahap ini kita memutuskan jika perangkat lunak, situs, dan pengguna siap untuk dioperasionalkan, tanpa memaparkan proyek untuk resiko tinggi. Rilis ini sering disebut sebagai rilis "beta". Transisi mungkin harus ditunda oleh satu rilis jika proyek gagal mencapai tonggak. Fase ini akan menghasilkan Implementation Strategy, Implementation Model, dan Tested System

\section{1) Implementation Strategy}

Untuk menyempurnakan rencana proyek untuk tahap selanjutnya development. Rencana proyek dapat diperbaharui dangan maksud untuk pembangunan yang actual.

\section{2) Implementation Model}

Implementation Model adalah artefak, komposit komprehensif yang mencakup semua artefak yang dibutuhkan untuk membangun dan mengelola sistem dalam lingkungan run-time. Realisasi yang dilakukan adalah pembuatan source code, membuat deskripsi, data base, dan map dari keseluruhan topology dari sistem.

\section{3) Tested System}

Tujuan dari tahap ini adalah untuk menrapkan dan menjalankan prosedur tes dengan cara eisien dan efektif. Prosedur pengujian akan memetakan dengan kebutuhan fungsional dan non fungsional dan dapat berada diberbagai tingkatan dalam arsitektur perangkat lunak.

\section{DSDM Implementation Phase Combine RUP Transition}

Pada fase terakhir ini mencakup transisi dari lingkungan pengembang ke lingkungan operasional. Itu tujuan utama dari tahap ini adalah untuk menempatkan sistem diuji dalam lingkungan pengguna bekerja dan melatih individu. Kebutuhan pengembangan masa depan juga dibingkai dalam fase ini. Sebuah tinjauan incremental dokumen yang digunakan untuk menggambarkan kegiatan perencanaan untuk peningkatan selanjutnya. Untuk tahapan ini akan mengeluarkan User Documentation, Installation Deliverables, Training User, dan Release Notes.

\section{1) User Documentation}

Berfungsi untuk menjelaskan kepada pengguna bagaimana menggunakan sistem.

\section{2) Installation Deliverables}

Berfungsi untuk memungkinkan sesorang menginstall produk. Deskripsi komponen, skrip instalasi, dan setiap isu yang terkait dengan proses instalasi.

\section{3) Training User}

Berfungsi untuk melakukan pelatihan langsung kepada operasional tentang penggunaan sistem baru yang telah dibuat.

\section{4) Relates Notes}

Ttujuannya untuk menggambarkan rilis sistem. Setiap cacat diketahiui dan masalah akan dijelaskan dalam dokumentasi ini.

\section{MANFAAT PENERAPAN SiSTEM INFORMASI}

Dengan telah dibuatnya Sistem Informasi Olahraga pada organisasi PBTI maka didapatkan manfaat yang dapat mendukung PBTI dalam mencapai visi dan misi organisasi. Manfaat-manfaat tersebut adalah :

\section{A. Aplikasi Pendaftaran Ujian Kenaikan Tingkat (UKT) Online}

Dengan adanya aplikasi ini maka kegiatan Pengprov PBTI dalam urusan ujian kenaikan tingkat sabuk semakin ringkas. Dari sebelumnya tahapannya Taekwondoin $\rightarrow$ Club $\rightarrow$ Pengkab/Pengkot -> Pengprov dengan berkas pendaftaran yang sangat banyak, menjadi Taekwondoin -> Pengkab/Pengkot -> Pengprov tanpa berkas pendaftaran karena semua dilakukan online. Kemudia semua data ujian tersimpan didalam database, sehingga apabila ada sertifikat Taekwondoin yang hilang maka akan segera dapat dicek didatabase untuk dibuat yang baru. Dengan adanya database ujian kenaikan dapat dilakukan verifikasi keaslian sertifikat sabuk, karena selama ini banyak beredar sertifikat sabuk yang palsu. PBTI juga dapat mengetahui jumlah pasti taekwondoin di Indonesia.

Kesulitan utama yang dihadapai pada peng Implementasian aplikasi ini adalah, pada proses peng integrasian data Sabuk Taekwondoin dari masa lalu hingga masa sekarang yang masih tersimpan manual. Pada proses pengintegrasian harus hati-hati karena jika salah, akan mengakibatkan kerugian pada seorang Taekwondoin pada proses ujian kenaikan sabuk selanjutnya. 


\section{B. Aplikasi Pengelolaan Kejuaraan}

Pada aplikasi ini data-data yang diolah adalah jadwal pertandingan, nama juara, dan ketersediaan wasit. Manfaat yang didapatkan oleh PBTI dengan adanya aplikasi ini adalah PBTI dapat mengontrol kejuaraan sehingga bisa dilakukan berkesinambungan. Apabila disuatu daerah jumlah sabuk biru keatasa nya sudah mencapai target(diketahui melalui aplikasi UKT), maka Pengprov akan segera mengadakan kejuaraan untuk mendapatkan bibit muda. Database wasit dapat dimanfaatkan untuk mencetak wasit-wasit kejuaraan. Setiap wasit memiliki jenjang karir, dengan adanya aplikasi ini wasit yang telah sering turun dikejuaraan akan terdata oleh aplikasi, wasit tersebut di promosikan ke tingkat nasional dan seterusnya. Setiap nama-nama juara disetiap kejuaraan akan didata dan di ikut sertakan tes untuk masuk ke pemusatan latihan daerah.

\section{Aplikasi Pengembangan Atlet}

Aplikasi pengembangan atlet berguna dalam hal pembinaan dan manajemen latihan atlet. Selama ini pembinaan atlet taekwondo dalam hal melihat progress atlet hanya menggunakan insting pelatih. Dengan adanya aplikasi ini semua data latihan atlet diolah oleh sistem. Sehingga untuk melihat perkembangannya dapat dilihat melalui grafik. Setiap data medis dari atlet disimpan dan diolah oleh sistem. Salah satu contoh manfaatnya adalah seorang atlet perempuan pasti mengalami mens setiap bulan, sering atlet tersebut batal ikut kejuaraan karena hal tersbut. Dengan adanya sistem yang mengolah data medis atlet maka sistem sudah memberikan warning kepada pelatih untuk melakukan penanggulangan medis kepada atlet sebelum terkena mens, agar atlet perempuan tetap bisa mengikuti kejuaraan.

\section{PENUTUP}

\section{A. Kesimpulan}

Saat ini, sebagian besar manajemen informasi olahraga masih dikumpulkan dan dianalisis data dengan tangan, dengan teknologi informasi sedikit demi sedikit diterapkan pada manajemen olahraga, dapat meningkatkan efisiensi untuk pengumpulan informasi dan analisis. Dalam paper ini, penulis mencoba menerapkan sistem informasi dalam pelakasanaan kegiatan organisasi olahraga dalam hal mengumpulka, menganalisis, mengintegrasikan informasi dan mencapai tujuan pelatihan pemain. Informasi kejuaraan selama ini dilakukan hanya dengan mencatat dalam kertas, dengan adanya penerapan sistem informasi pada pengelolaan kejuaraan, semua kegiatan kejuaraan dapat lebih terkoordinir. Dengan adanya aplikasi pengembangan atlet, informasi relevan yang dapat mengidentifikasi kekuatan dan kelemahan atlet.

Dalam paper ini memiliki sebuah sistem, dengan cara penerapan sistem informasi merubah cara tradisional pengumpulan data menjadi cara yang lebih canggih dengan bantuan teknologi informasi.

\section{DAFTAR PUSTAKA}

[1] Abrahamsson, P., Salo, O., and Ronkainen, J., "Agile Software Development Methods" in : VTT Publications.

[2] Avison, D. E., dan Myers, M. D. "Information system and Anthropology : An Anthropological Perspectives on IT and Organizational Culture". Information Technology \& People, 10(3), 43-56.

[3] Baskerville, R. L. "Investigating Information System as A Reference Discipline. MIS Quarterly.

[4] Jacobson, I., Booch, G., and Rumbaugh, J., "The Unified Software Development Process. In : Addison-wesley.

[5] Lin, J., Sheng-Hsiung Tsai., and Yi-Hsing Chang., "A Sports Information Management System based On Pervasive Computing Technology".

[6] Sun, J., "The Establishment of Sports System Engineering" in: International Journal of Sports Science and Engineering.

[7] Honari, H., "Information Technology in Profesional Sports" in : International confrence on Environmental, Biomedical and Biotechnology. 